\title{
REVISĀO FITOESTRATIGRÁFICA DO GRUPO ITARARÉ NO RIO GRANDE DO SUL. I. ACAMPAMENTO VELHO, CAMBAI GRANDE, BUDÓ E MORRO PAPALÉO
}

\author{
MIRIAM CAZZULO-KLEPZIG \\ MARGOT GUERRA-SOMMER \\ GERARDO EUGENIO BOSSI
}

Curso de Pós-graduação em Geociências, UFRGS

\section{RESUMO}

O conteúdo paleoflorístico dos afloramentos Acampamento Velho, Cambaí Grande, Budó e Morro Papaléo é revisado criticamente, incluindo perfís estratigráficos detalhados com localização dos níveis fossilíferos. Foram assinalados vários gêneros de plantas, registrados anteriormente apenas para Morro Papaléo e Acampamento Velho, destacando-se, de modo especial, a presença de Rubidgea Tate 1867, também reconhecida nas tafofloras de Bajo de Velis (Argentina) e Cerquilho (São Paulo), datadas como Sakmariano.

Os elementos vegetais e invertebrados marinhos são encontrados em camadas superpostas, às vezes mesclados.

A paleoflora encontrada nos afloramentos Cambaí Grande e Acampamento Velho (onde ocorrem invertebrados) é aloctone e foi transportada de áreas emersas vizinhas, não existindo por- 
tanto, níveis marinhos e continentais intercalados; os perfís começam com arenitos grosseiros, que indicam facies litorâneas, talvez continentais, as quais passam rapidamente, para cima, a siltitos marinhos finamente estratificados. A passagem, sem facies de praia definidas, pode significar a rápida ingressão do mar numa área de relevo irregular.

No afloramento Morro Papaléo não se evidenciou a presença de invertebrados marinhos, enquanto que no afloramento Budó foram registrados apenas restos de organismos marinhos, sem confirmar a presença de Flora-Glossopteris.

\section{ABSTRACT}

Some classic outcrops (Acampamento Velho, Cambai Grande, Morro Papaléo and Budó) of the Itararé Group in Rio Grande do Sul (Brazil) are reviewed critically.

Several fossil plant genera, previously registered only for Acampamento Velho and Morro Papaléo, were recognized also at Cambai Grande, being relevant the presence of Rubidgea Tate 1867, also known from Bajo de Velis (Argentina) and Cerquilho (São Paulo).

The flora suggests a Sakmarian age.

Plants were found in several horizons associated with marine invertebrates.

The paleoflora of Acampamento Velho and Cambai Grande is allochthonous and was transported to the marine environment from nearby emerged areas.

All profiles start with paraconglomerates and/or cross-bedded conglomeratic sandstones deposited in a continental environment, that shift abruptly into a fine bedded marine silty-sandstone and siltstones.

The is no transition between such facies, which could indicate a very rapid sea ingression onto an irregular landscape.

The Budó outcrop is the only one with no trace of Glossopteris flora associated with the marine fossils.

\section{INTRODUÇÃO}

Na tentativa de ampliar os conhecimentos sobre os problemas bioestratigráficos do Grupo Itararé no R.G. Sul e com o objetivo de iniciar uma análise mais detalhada das associaçōes paleoflorísticas dos principais afloramentos fossilíferos registrados para essa unidade foi elaborado o presente trabalho.

Foram efetuados perfís estratigráficos detalhados, revisão dos mapas de localização dos afloramentos, descrição dos espécimes vegetais coletados e caracterização das diferentes associações.

Sob estes aspectos foram analisados os afloramentos Cambaí Grande, Acampamento Velho, Morro Papaleó e Budó, já estudados por outros autores.

A revisão crítica das citações paleoflorísticas baseou-se na necessidade de definir melhor as características dos espécimes até agora citados na bibliografia, pois tem se observado, com freqüência, que no registro das formas vegetais estão ausentes detalhes de descrição, ilustrações ou mesmo comparações com formas similares. Também, de modo geral, o material-tipo encontra-se extraviado, surgindo daí dúvida quanto à caracterização genérica das formas citadas.

Formas referidas em diversos afloramentos como Phyllotheca, por exemplo, provavelmente devem indicar impressões de Paracalamites, por tratar-se de caules articulados desprovidos de folhas. No caso do gênero Gangamopteris, verifica-se que muitas vezes as citações devem corresponder a outro tipo de folha glossopterídea, como, por exemplo, Rubidgea.

Afloramentos novos, como Faxinal e Fazenda Goulart constituem tema de outros trabalhos que deverão integrar a revisão fitoestratigráfica do Itararé no Rio Grande do Sul.

As amostras aqui analisadas integram a Coleção Paleobotânica do Departamento de Paleontologia e Estratigrafia do Instituto de Geociências, UFRGS. 


\section{AFLORAMENTO CAMBAI GRANDE}

- Localização: De acordo com Dohms (1977), é a seguinte a localização desse afloramento: "Seguindo a Rodovia BR-290 (GuaíbaUruguaiana) ao chegar à localidade de Vila Nova toma-se a estrada para São Gabriel, via Cambaí Grande. A $14 \mathrm{~km}$ de Vila Nova encontra-se um afloramento no lado sul da estrada (no acostamento) e, pouco mais adiante, no lado norte da mesma rodovia (e igualmente no mesmo acostamento) outro afloramento, apresentando uma camada de aproximadamente $10 \mathrm{~cm}$ de espessura, com restos fósseis vegetais, diretamente acima do conglomerado (30 ${ }^{\circ} 17^{\prime} 53^{\prime \prime} \mathrm{S}$ e $53^{\circ} 59^{\prime} 22^{\prime \prime} \mathrm{W}$ de Greenwich)."

Folha Vila Nova (SH-22-M-I-3). Município de São Gabriel.

- Consideraçôes Estratigráficas e Paleontológicas: A extensão aparente dos afloramentos e suas relações estão indicadas na figura 2 . Reconhecem-se dois setores separados por uma falha com direção $31^{\circ}$ mergulhando para $\mathrm{S} 10^{\circ}$ ao $\mathrm{N}$, localizados entre blocos sobrelevados do Embasamento.

A sequêencia compreende um máximo de $60 \mathrm{~m}$ de espesssura, divididas em duas seções bem definidas. A seção inferior, que jaz discordantemente sobre o Embasamento cristalino consiste em arcósios grossos a conglomeráticos, cinza-pardacentos, estratificados em camadas grossas a finas, com laminação cruzada tabular, parcialmente cimentados por carbonatos. Ela adquire um desenvolvimento maior no afloramento B (fig. 2) onde alcança sua máxima espessura. Através de pulsações marcadas, passa à seção superior que consiste em arenitos silticos cinza claros, com laminação plano-paralela a plano-irregular na base, tornando-se progressivamente maciços até o topo.

A parte basal dessa seção contém abundantes impressōes vegetais que ocorrem em níveis comparáveis nos dois afloramentos.

Segundo Martins e Sena Sobrinho 1950, o conteúdo paleontológico é constituído por Brachiopoda e Mollusca: Orbiculoidea guarauensis Oliveira 1930 e Langella imbituvensis Oliveira 1930 .

Correa da Silva (1977) refere-se a registros paleoflorísticos feitos para esse afloramento por Pinto (1955) de modo equívoco, erro esse repetido por Lockzy (1964), Zingano e Cauduro (1959), Barcellos (1973) Pinto e Purper (1974) e Dohms (1977) os quais citam a ocorrência de restos de Phyllotheca, Gangamopteris e Glossopteris.

Os trabalhos agora realizados permitiram fazer observações importantes:

19) O perfil apresentado por Barcellos (1973) foi retificado. (fig. 2)

2.9) Há um nível fossilifero contendo abundante número de impressø̄es de conchas de Brachiopoda e Mollusca que caracterizam uma fauna eminentemente marinha, situado na parte superior da seqüência sedimentar, conforme perfil da fig. 2 , no qual aparecem associados restos de algas filamentosas, indeterminadas.

Nesse nível é grande a freqüência de conchas de Pelecypoda que estão classificados por Barcellos (1973) como Aviculopecten cambayhensis Martins 1951.

Essas conchas são finas, delicadas e se distribuem em orientação irregular, muitas vezes em superposição.

30) À medida em que se desce na seqüência, diminui a ocorrência de conchas e aumenta a concentração de algas, até atingir um nível de abundantes restos vegetais, que tem sido referido por diversos autores, principalmente Barcellos (op. cit.) e Correa da Silva (1977).

Esse nivel, assinalado no perfil da fig. 2, tem sido citado como um nível de plantas; mas ele contém, além dos restos vegetais, escassas impressões de conchas.

- Conteúdo Paleobotânico - De modo amplo, assim pode ser expressa a composição geral da associação paleoflorística na amostragem coletada:

$\begin{array}{lr}\text { Gangamopteris } & 55 \% \\ \text { Samaropsis } & 18 \% \\ \text { Cordaites } & 16 \% \\ \text { Algas não identificadas } & 10 \% \\ \text { Frutificação } & 1 \% \\ \text { Glossopteridophyta } & \end{array}$

Glossopteridophyta

Gênero Gangamopteris McCoy, 1860

1847 - Cyclopteris angustifolia McCoy, $20: 148$ est. 9 , fig. 3 e 3 a.

1875 - Gangamopteris angustifolia McCoy, $2: 11$ est. 12 , fig. 1 ; est. 13 , fig. 2 e 2a-Mudgee, N. Walles, Austrália. Gangamopteris angustifolia McCoy, 1875 (Est. I, fig. 8) 
- Descrição: O material é constituído por dois fragmentos da porção mediana de folhas linear-lancioladas, nas quais os bordos são inteiros, subparalelos e se estreitam um pouco em direção à extremidade. Nos dois fragmentos faltam as porções basal e apical. O fragmento maior mede $13 \mathrm{~cm}$ de comprimento por $1,5 \mathrm{~cm}$ de largura. Ao longo da parte mediana corre um feixe de diversas nervuras subparalelas que arqueiam-se suavemente e chegam às margens em ângulo agudo.

A bifurcação das nervuras é pouco nítida, mas parece ser mais freqüente na porção marginal da folha (fig. 8).

O número de nervuras embora pouco observável deve oscilar em torno de 10 por centímetro.

- Comparação: As formas diferem de Gangamopteris obovata, por apresentarem curvatura muito suave das nervuras (em Gangamopteris obovata as nervuras partem em ângulo de mais ou menos $45^{\circ}$ do feixe central).

Gangamopteris buriadica Feistmantel, 1879

(Est. I, fig. 1, 2 e 5)

1977 - Gangamopteris buriadica: Correa da Silva e Arrondo, p. 33 - est. I, fig. 5 .

- Descrição: Os fragmentos são incompletos e correspondem alguns à parte apical de folha, outros à parte mediana. A forma do limbo é oblongo-espatulada com largura de 2,5 a $3 \mathrm{~cm}$ na sua parte média.

Da parte basal parte um feixe central de nervuras subparalelas que atravessam toda a lâmina foliar, encurvam-se em direção às margens e se dicotomizam, formando areolas alongadas, pouco evidentes.

Na extremidade da folha a nervação abrese em forma de leque.

Na parte média da folha a densidade das nervuras oscila entre 20 a 22 por centímetro (Estampa I, fig. 5).

- Comparação: As formas descritas tem características muito similares aos espécimes descritos por Dolianiti 1954 para região de Acampamento Velho e por Correa da Silva e Arrondo (1977) para Mariana Pimentel, ambas no Rio Grande do Sul, como Gangamopteris buriadica Feistmantel.

As nervuras atingem o bordo em ângulo mais aberto do que o que ocorre em Gangamopteris obovata. Também a extremidade da folha é um pouco mais aguda do que em Gangamopteris obovata.

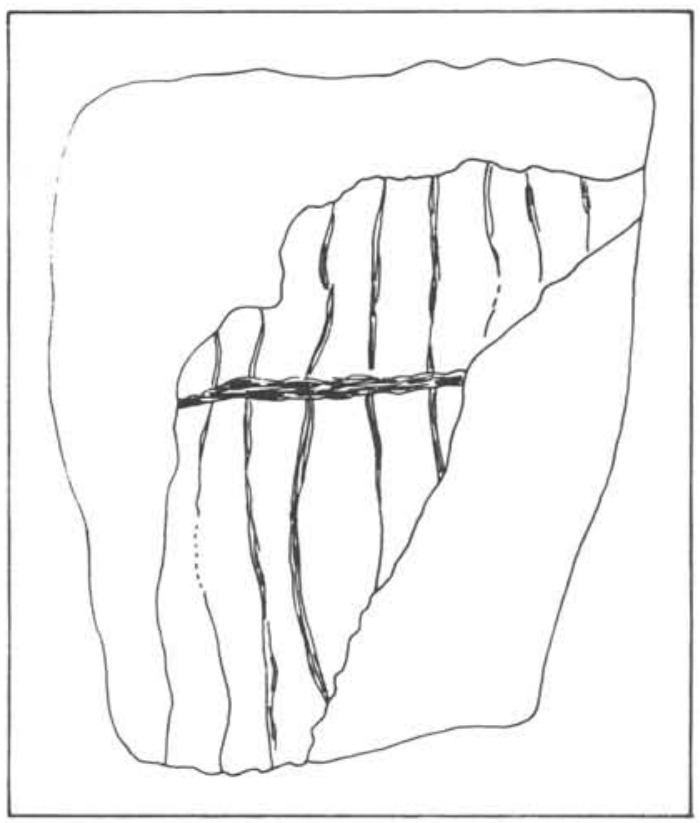

Fig. de texto 1 - Paracalamites cfr, austrália Câmara clara $-\times 6$

\section{ESTAMPA I (CAMBAI GRANDE}

1 - Gangamopteris buriadica Feistmantel $-\times 2$.

2 - Gangamopteris buriadica Feistmantel $-\times 2$.

3 - Cordaites sp. $-\times 1,5$.

4 - Gangamopteris buriadica Feistmantel $-\times 1,5$.

5 - Gangamopteris buriadica Feistmantel $-\times 1,5$

6 - Gangamopteris obovata (Carr.) White $-\times 1,5$.

7 - Gangamopteris buriadica Feistmantel $-\times 1,5$.

8 - Gangamopteris angustifolia McCoy - x 1 (com impressão de concha no mesmo nivel). 
Páleobotânica e Áreas Afins na América do Sul _ Bol. IG. Instituto de Geociências, USP, V. 11: 31-189, 1980

ESTAMPA ।
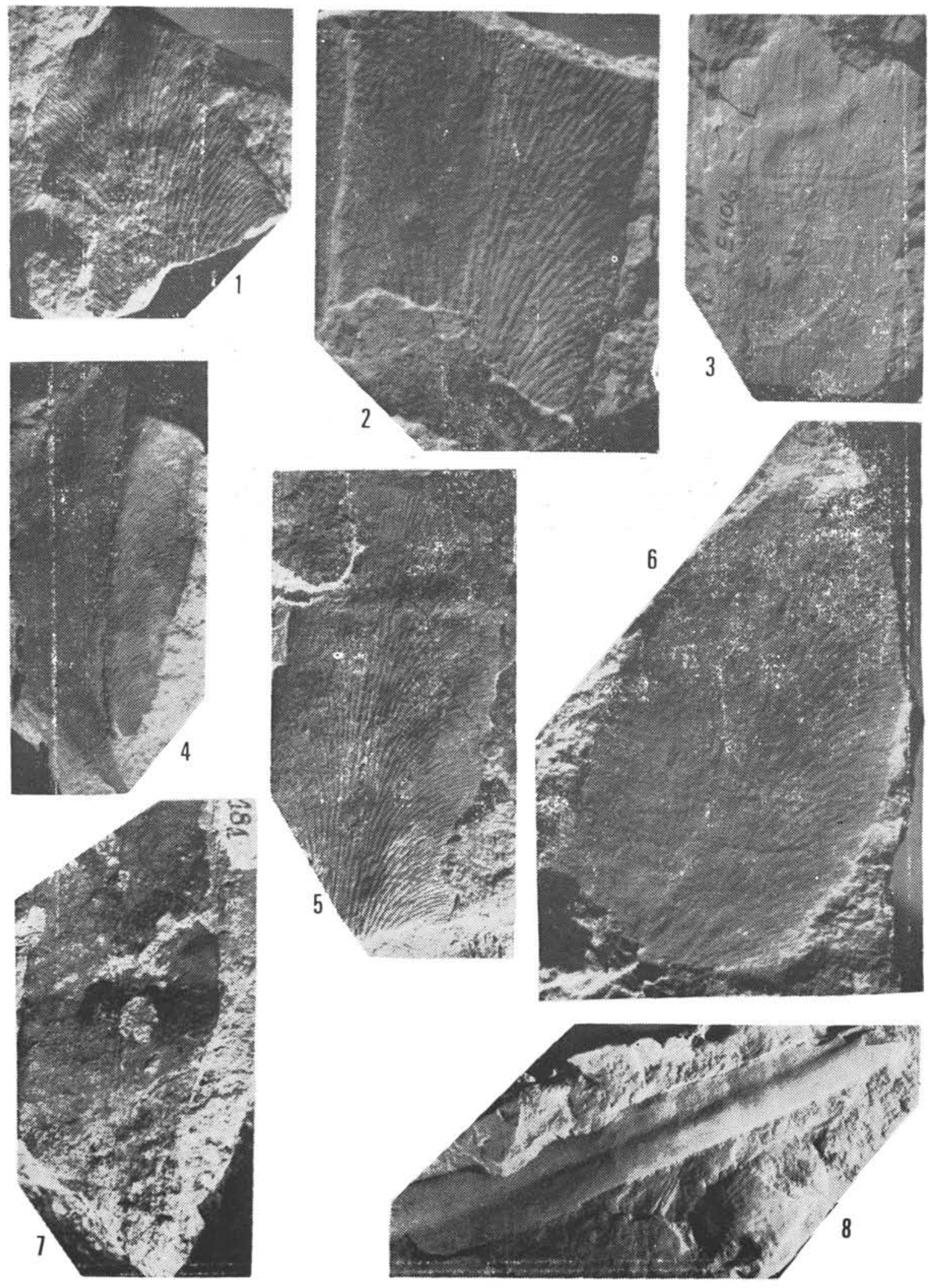

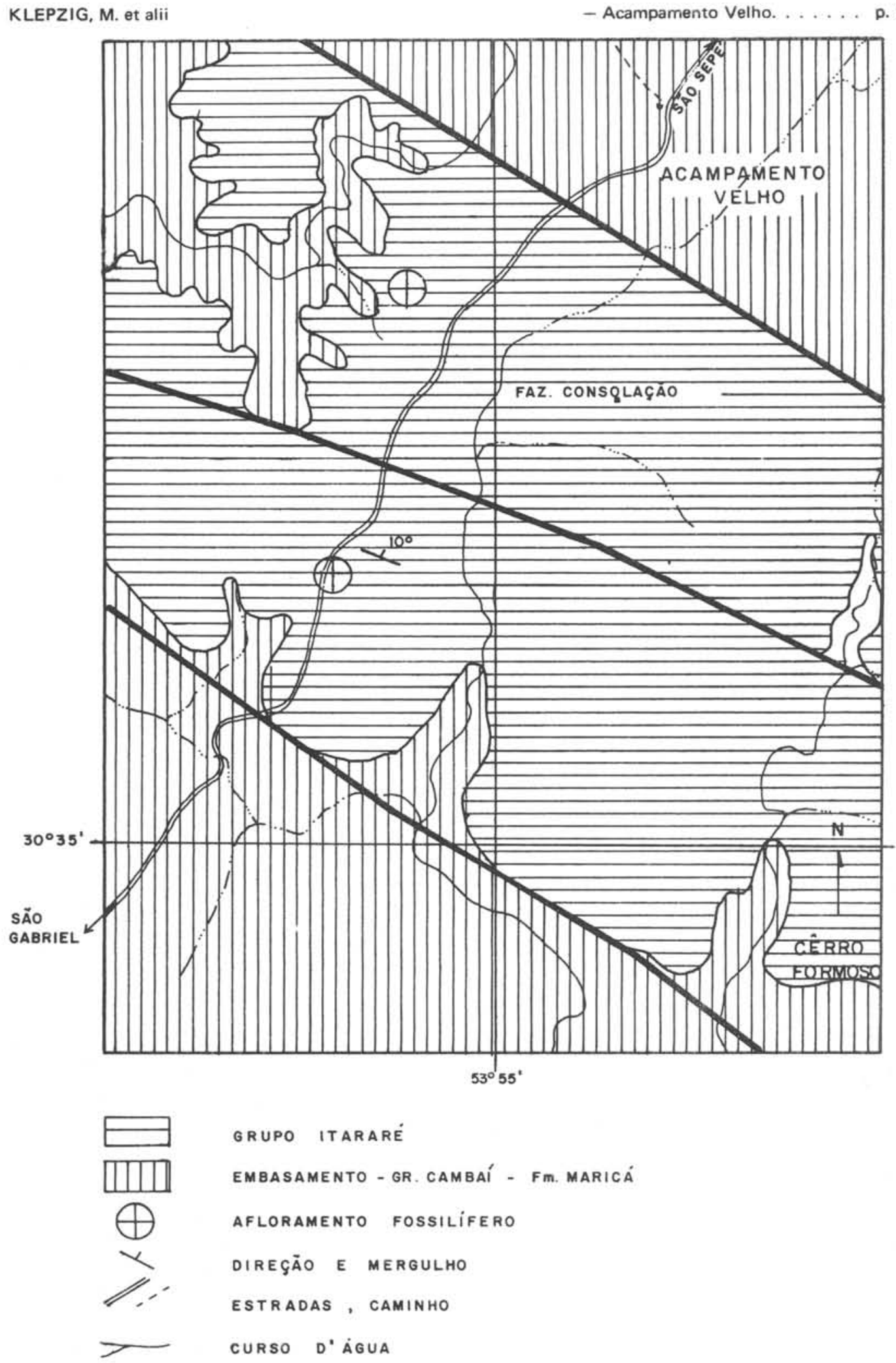

Fig. 1 - esquema geológico dos afloramentos de ACAMPAMENTO VELHO(Seg. DOHMS, 1977 -modificodo). 
FIG. 2 - PERFIS ESTRATIGRÁFICOS DOS AFLORAMENTOS ACAMPAMENTO VELHO E CAMBAI GRANDE acampamento VElHo

AFLORAMENTO "A "

ESCORES TEXTURAIS

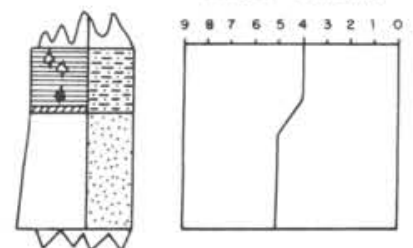

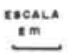

AFLORAMENTO" "
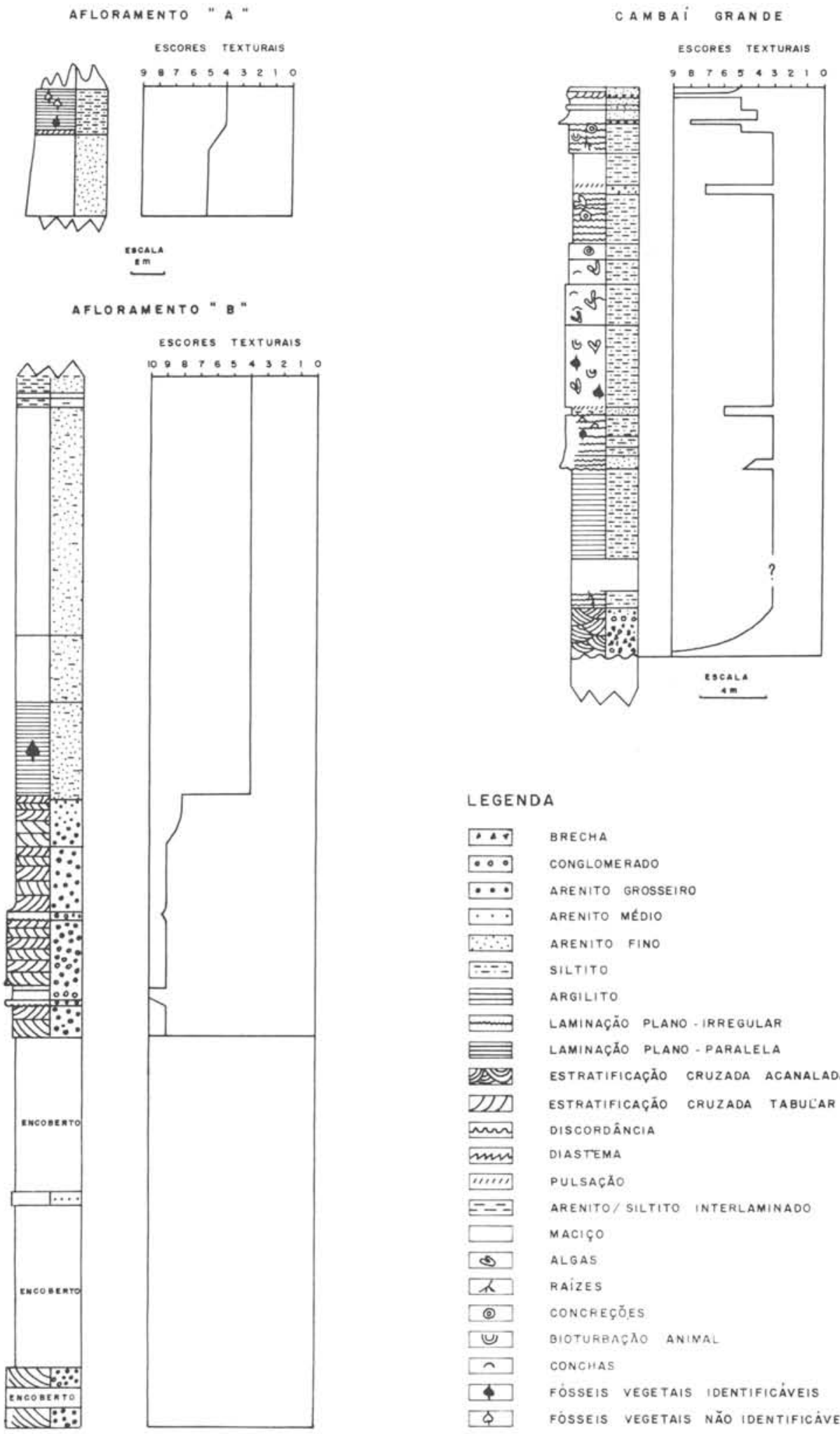

LEGENDA

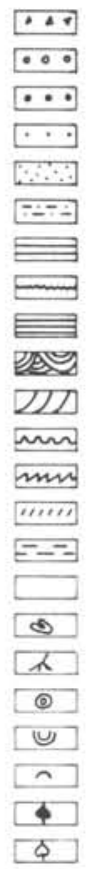

BRECHA

CONGLOMERADO

ARENITO GROSSEIRO

ARENITO MÉDIO

ARENITO FINO

SILTITO

ARGILITO

LAMINAÇÃO PLANO - IRREGULAR

LAMINAÇÃO PLANO - PARALELA

ESTRATIFICAÇÃO CRUZADA ACANALADA

ESTRATIFICAÇÁO CRUZADA TABUCAR

DISCORDÂNCIA

DIASTEMA

PULSACAO

ARENITO/SILTITO INTERLAMINADO

MACIÇO

ALGAS

RAIZES

CONCREÇÕLES

BIOTUREAÇO ANIMAL

CONCHAS

FÓSSEIS VEGETAIS IDENTIFICÁVEIS

FÓSSEIS VEGETAIS NĂO IDENTIFICAVEIS

Des nuvia of eagted 


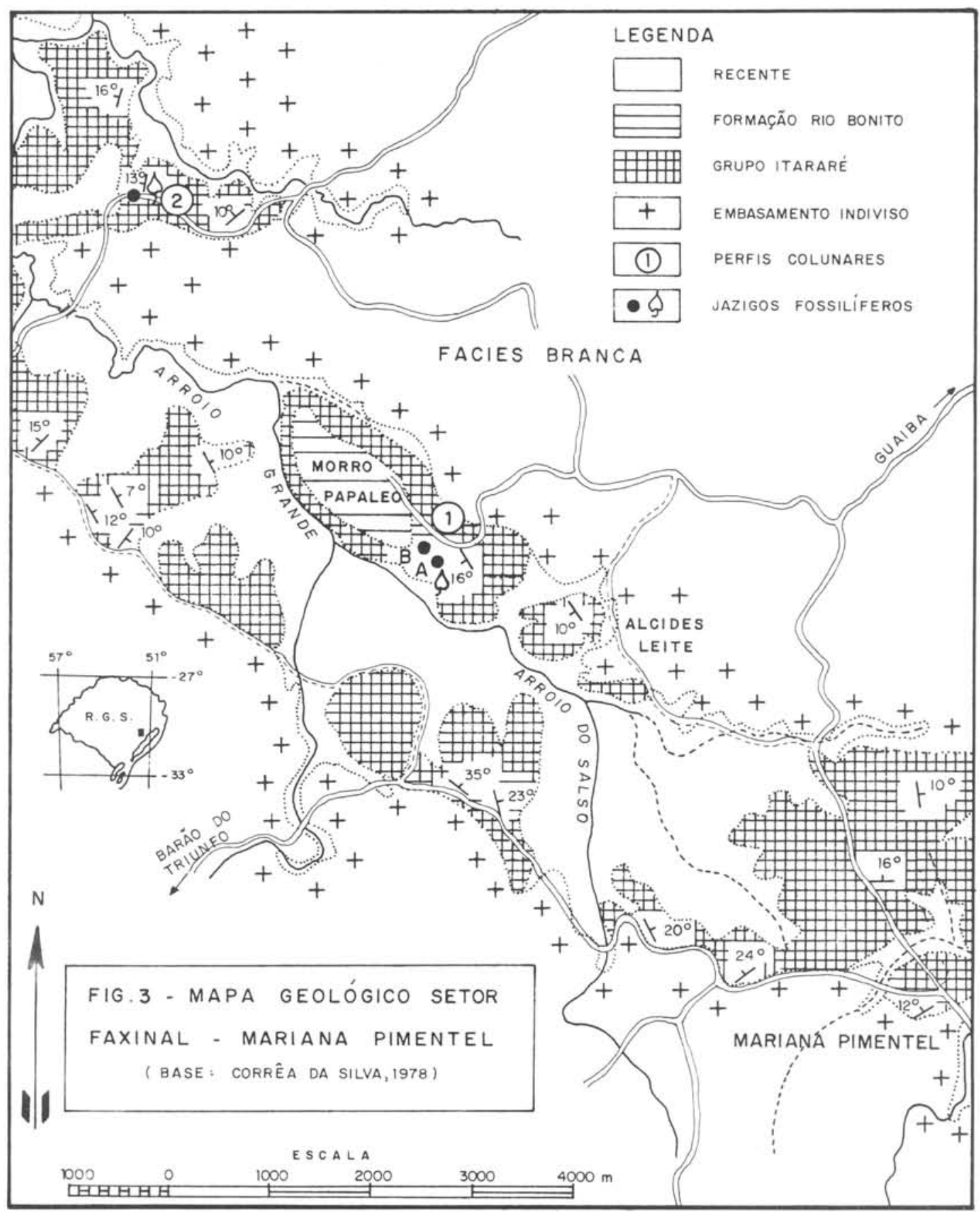


Quanto a Gangamopteris mosesii Dolianiti, os exemplares tem malhas mais longas e densidade das nervuras mais uniforme a partir da parte mediana até o bordo, ao contrário do que é citado para aquela espécie. Também a extremidade na Gangamopteris mosesii é muito mais aguda.

\author{
Gangamopteris obovata (Carru- \\ thers) White, 1908 \\ (Est. I, fig. 6) \\ 1977 - Gangamopteris obovata Oliveira, \\ pg 175 \\ - Descrição: O material é constituído
} por fragmentos de folhas oblongo-lanceoladas, com base estreita e constrita e margens onduladas. A parte apical da folha não foi preservada. A largura máxima da folha (parte mediana) atinge $2,5 \mathrm{~cm}$ e o maior fragmento tem um comprimento observável de $6,5 \mathrm{~cm}$ (aparentemente o comprimento total seria de até $10 \mathrm{~cm}$ ). Ao longo da parte mediana ocorre um feixe de 4 a 5 vias subparalelas. As vias laterais se bifurcam várias vezes, curvam-se e atingem o bordo num ângulo de $\pm 50^{\circ}$.

A densidade das nervuras atinge 18 a 20 por centímetro (Estampa I, fig. 6).

- Comparação: O espécime estudado é muito semelhante ao descrito por Dolianiti (1954) para o afloramento Bainha, Santa Catarina, como Gangamopteris obovata var. major Feistmantel.

A curvatura suave das nervuras laterais e o tipo de venação são semelhantes a Gangamopteris cyclopteroides Feistmantel mas o aspecto geral da folha a diferencia dessa espécie.

\section{Cordaites sp}

(Est. I, fig. 3)

Consideraçôes sobre a distinção entre os gêneros Cordaites e Noeggerathiopsis:

A separação dos 2 gêneros foi proposta inicialmente por Feistmantel (1890) com base na distribuição geográfica, porém os trabalhos de Seward e Sahni (1920) concluem por ser exagerada essa separação.

Florin (1936) separa os dois gêneros com base em distribuição dos estomas, critério esse comprovadamente duvidoso, pois em ambos os gêneros podem ocorrer diversos tipos de distribuição dessas estruturas.
Pant e Verma (1964) separam os dois gêneros, baseados nas seguintes características:

- tamanho maior e forma ovadada em Cordaites.

- tamanho menor e forma espatulada em Noeggerathiopsis.

- presença de fibras intersticiais entre as veias em Cordaites, e pouca freqüência dessa característica em Noeggerathiopsis.

- distribuição de estomas em poucas fileiras regulares ( 1 ou 2 em Cordaites) e maior número, mal definidas, em Noeggerathiopsis.

- distribuição geográfica.

Esses autores mantém a separação entre os 2 gêneros, com base em:

19) predomínio de algumas diferenças estruturais da epiderme entre os mesmos.

20) ausência de frutificação do tipo Cordaianthus em Flora de Glossopteris.

3.) imperfeito conhecimento da estrutura interna dos talos de Noeggerathiopsis.

Eles aceitam que há gêneros comuns entre a região do Gondwana e Euro-americana, e que existem argumentos para considerar a fusão dos gêneros, mas optam por conservar a separação dos mesmos.

Meyen (1963, 1967, 1971) estabelece características importantes que devem ser observadas nas folhas de Cordaites, como densidade da venação, espessura das veias, arqueamento e divergência das veias e falsas vênulas. Esse autor estabelece, em 1963, um novo gênero Rufloria com o abandono do nome Noeggerathiopsis.

As conclusōes de Meyen (1963) sobre a validade de Noeggerathiopsis como designação referem-se ao fato dele ter sido originalmente definido com base numa interpretação errônea (hábito pinado). Porém sabe-se que não há semelhança entre as Cordaites gondwânicas e as folhas angáricas do gênero Rufloria. Por esta razão, Archangelsky (1978) afirma que as folhas referidas aNoeggerathiopsis no Gondwana tem uma posição imprecisa a qual ele analisa fazendo as seguintes observações:

1) a espécie tipo, $N$. hislopi, não tem cutícula, originando dúvidas nas diagnoses de Pant e Verma (1964) e Maithy (1964).

2) os traços morfológicos externos apresentados nas emendas tanto podem correspon- 
der à diagnose de Cordaites como Rufloria.

3) trata-se apenas de questão nomenclatural - dentro do grupo das Cordaites são englobados tanto folhas como órgãos reprodutivos e outros órgãos vegetativos, devendo tratar-se de um grupo homogêneo e natural.

Com base nessas considerações, e como as amostras analisadas contém apenas impressôes de folhas, elas estão identificadas apenas como folhas de Cordaites (Estampa 1, fig. 3).

\section{AFLORAMENTO ACAMPAMENTO VELHO (Afloramentos A e B)}

- Localização: Conforme Dohms (1977) é a seguinte a localização do afloramento: "partindo de Porto Alegre pela Rodovia BR-290 (Guaíba-Uruguaiana) ao chegar na localidade de Vila Nova toma-se a estrada para Três Divisas (a SW de Ramada). Daí segue-se para São Gabriel, via Acampamento Velho, por aproximadamente $12 \mathrm{~km}$ (direção SW de Três Divisas) onde encontra-se uma área com vários afloramentos, sendo principais os dois seguintes: um afloramento artificial, chamado "pedreira", localizado a 600-800 metros pelo campo, no lado NW da estrada ( $30^{\circ} 35^{\prime} 24^{\prime \prime} \mathrm{S}$ e $53^{\circ} 57^{\prime} \mathrm{W}$ de Greenwich). Partindo de São Gabriel pela Rodovia BR-290, em direção à Porto Alegre, segue-se $24 \mathrm{~km}$ (onde se encontra a Oficina Santa Margarida) tomando-se então a estrada para Três Divisas. A partir desta localidade ruma-se da mesma forma citada acima".

Folha Arroio América (SH-22-M-III-1), Município de São Gabriel.

O mapa de localização indicado por Dohms (op. cit.) não identifica corretamente a situação dos dois afloramentos visitados e por essa razão foi feita uma alteração no mesmo, a qual aparece em destaque no mapa da fig. 1.

- Consideraçōes estratigráficas e paleontológicas - A seqüência se inicia com arcósios cinza-pardacentos, grossos, conglomeráticos, com estratificação cruzada que passam, mediante pulso acentuado, a siltitos cinza-claros com estratificação muito fina a fina, maciços, às vezes com laminação plano paralela a plano regular, com algumas intercalações de arenitos finos médios em camadas tabulares maciças ou com laminação cruzada.

Os dois terços inferiores são fossiliferos contendo impressōes de folhas, sementes e algas. No terço médio os restos vegetais aparecem misturados com conchas de Pelecypoda enquanto no terço superior ocorrem somente conchas e impressões de algas.

Uma revisão das diversas formas vegetais fósseis referidas na bibliografia existente permitiu separar o elenco paleoflorístico em duas categorias: formas citadas e formas identificadas.

Dentro das formas citadas, aparecem:

- Phyllotheca (Beurlen, Martins e Sena Sobrinho, 1955)

- Gondwanidium (Beurlen, Martins e Sena Sobrinho 1955)

Obs.: Correa da Silva (1977) cita esse registro como Botrychiopsis, utilizando a sinonímia do gênero estabelecido por Archangelsky e Arrondo, 1971.

- Gangamopteris obovata (Dolianiti, 1954 e Correa da Silva, 1977).

As formas identificadas anteriormente são:

- Phyllotheca (Martins e Sena Sobrinho, 1950 e Dolianiti, 1953)

- Gondwanidium plantianum (Dolianiti, 1954)

- Glossopteris sp (Martins e Sena Sobrinho, 1950 e Beurlen, Martins e Sena Sobrinho, 1955)

- Gangamopteris sp (Martins e Sena Sobrinho, 1950)

Trabalhos realmente descritivos das formas referidas para esse afloramento são representados pelo trabalho de Dolianiti (1954) que

ESTAMPA $\|$ (ACAMPAMENTO VELHO)

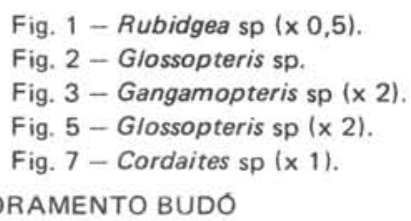

Fig. 4 -Chiropteris reniformis Kawasaki (x 2) Foto Dolianiti 1977.

Fig. 6 - Chiropteris reniformis Kawasaki (x 2) Foto Dolianiti 1977. 
Paleobotânica e Áreas Afins na América do Sul _ Bol. IG. Instituto de Geociências, USP, V. 11:31-189, 1980

- ESTAMPA II
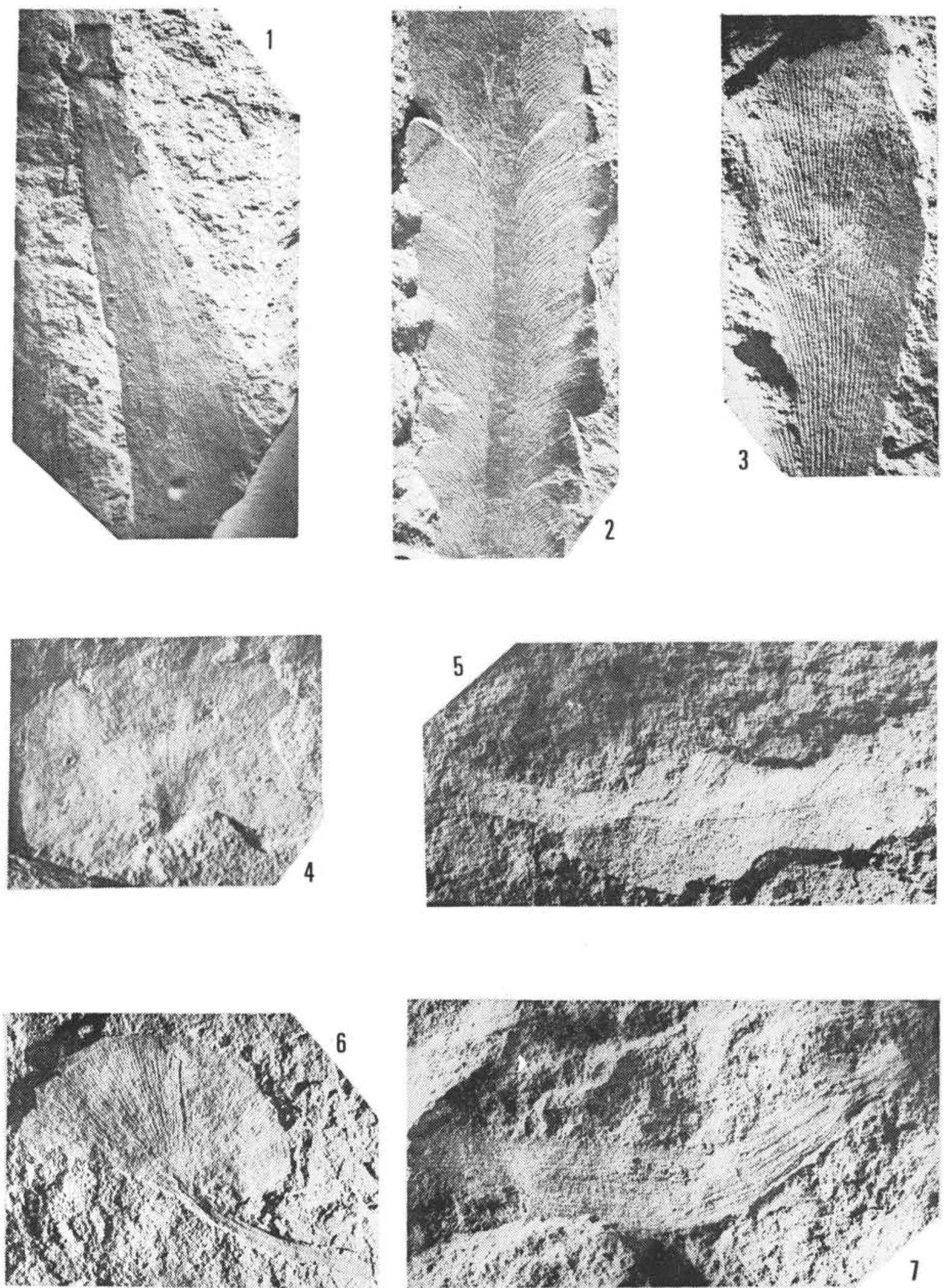
analisa e ilustra diversos espécimes de Gangamopteris buriadica, Gangamopteris angustifolia e Cordaites hislopi e também o trabalho de Beurlen, Martins e Sena Sobrinho (1955) que registra o gênero Gondwanidium, dando ênfase a essa ocorrência por representar uma forma pertencente à Flora Rhacopteris. Barcellos (1973) e Correa da Silva (1978) figuram um exemplar de Glossopteris sp, sem entretanto descrevê-lo (Est. II, fig. 2).

Nos afloramentos A e B foram coletadas amostras contendo impressōes de fragmentos de folhas de Gangamopteris sp (Est. II, fig. 3), Glossopteris sp (Est. II, fig. 5) e Cordaites sp (Est. II, fig. 7), bem como fragmentos de caules de Articuladas, provavelmente Paracalamites cf. $P$. australis (fig. de texto 1). $\hat{\mathrm{E}}$ assinalada ainda a presença do gênero Rubidgea (Est. II, fig. 1).

O material paleoflorístico é abundante, porém mal preservado, constando quase sempre de folhas fragmentadas.

As referencias a escamas de peixes e espiculas de Porífera (Correa da Silva, 1970) e restos de Brachiopoda (Martins e Sena Sobrinho, 1950) não foram comprovadas.

Também os registros anteriores de Phyllotheca devem referir-se, provavelmente, a caules tipo Paracalamites, pois não foram encontrados caules articulados providos de folhas.

\section{INTERPRETAÇĀO PALEOAMBIENTAL DAS SEQUENCIAS}

Os dois perfis descritos se caracterizam pela presença de duas seções litologicamente bem definidas e contrastantes, situação que se repete também no afloramento Budó. (fig. 2)

A seção inferior constituída por arcósios grossos parece corresponder a um ambiente de alta energia, possivelmente fluvial ou glacio-fluvial, acumulando-se esses sedimentos em bacias em áreas baixas do relevo circundante (setor ocidental do Escudo sulriograndense).

A pulsação já referida determina a rápida implantação de um ambiente marinho calmo. Em nenhum dos perfis reconhecidos, observa-se transição ou facies de transição entre os litotopos. As texturas finas, próximas ao limite areia-silte e a prẹdominância de estratificação fina, às vezes laminadas, indica condições de baixa energia, sedimentação tranqüila em fundos bem oxigenados; cores cinzentas muito claras e abundância de algas, reforçam essa evidência.

A ausência de marcas de ondas e de estratificação cruzada bem desenvolvida indicaria uma influência escassa de marés.

As baias ocorreram em costas profundamente denteadas de mar localizadas a Oeste do

ESTAMPA III (MORRO PAPALÉO)

Fig. 1 - Buriadia heterophylla (Brongn.) Seward e Sahni (Foto Correa da Silva/Arrondo) $-x 2$

Fig. 2 - cf. Nephropsis sp. (Foto Correa da Silva e Arrondo, 1977) - 1 .

Fig. 3 - Chiropteris sp. $-\times 2$.

Fig. 4 - Samaropsis (White) Seward (Foto Correa da Silva e Arrondo 1977) - x 2 .

Fig. $5-$ Rubidgea sp. $-\times 2$.

Fig. 6 e 10 - Ginkgophyllum criciumensis (Rigby) Archangelsky e Arrondo (Foto Correa da Silva e Arrondo 1977) $-\times 1$.

Fig. 7 - Glossopteris indica Schimper (Foto de Correa da Silva e Arrondo 1977) - $x 1$.

Fig. 8 - Gangamopteris sp. (enrolada) $-\times 5$.

Fig. 9 - Gangamopteris obovata (Carr) White (Foto Correa da Silva e Arrondo 1977) - x 2.

Fig. 11 - Gangamopteris sp (Foto Correa da Silva e Arrondo 1977).

Fig. 12 - Cordaites sp. $-\times 1$.

Fig. 13 - Paracalamites cf. australis Rigby (Foto Correa da Silva e Arrondo 1977) - x 1.

Fig. 14 - Gangamopteris angustifolia McCoy (Foto Correa da Silva e Arrondo 1977) - $x 1$.

Fig. 15 - Glossopteris indica Schimper (Foto Correa da Silva Arrondo 1977) - x 1.

Fig. $16-$ Fertiliger (Ottokaria) Schopf $1976-\times 2$. 
Paleobotânica e Áreas Afins na América do Sul _ $\quad$ Bol. IG. Instituto de Geociências, USP, V. 11: 31-189, 1980

ESTAMPA III
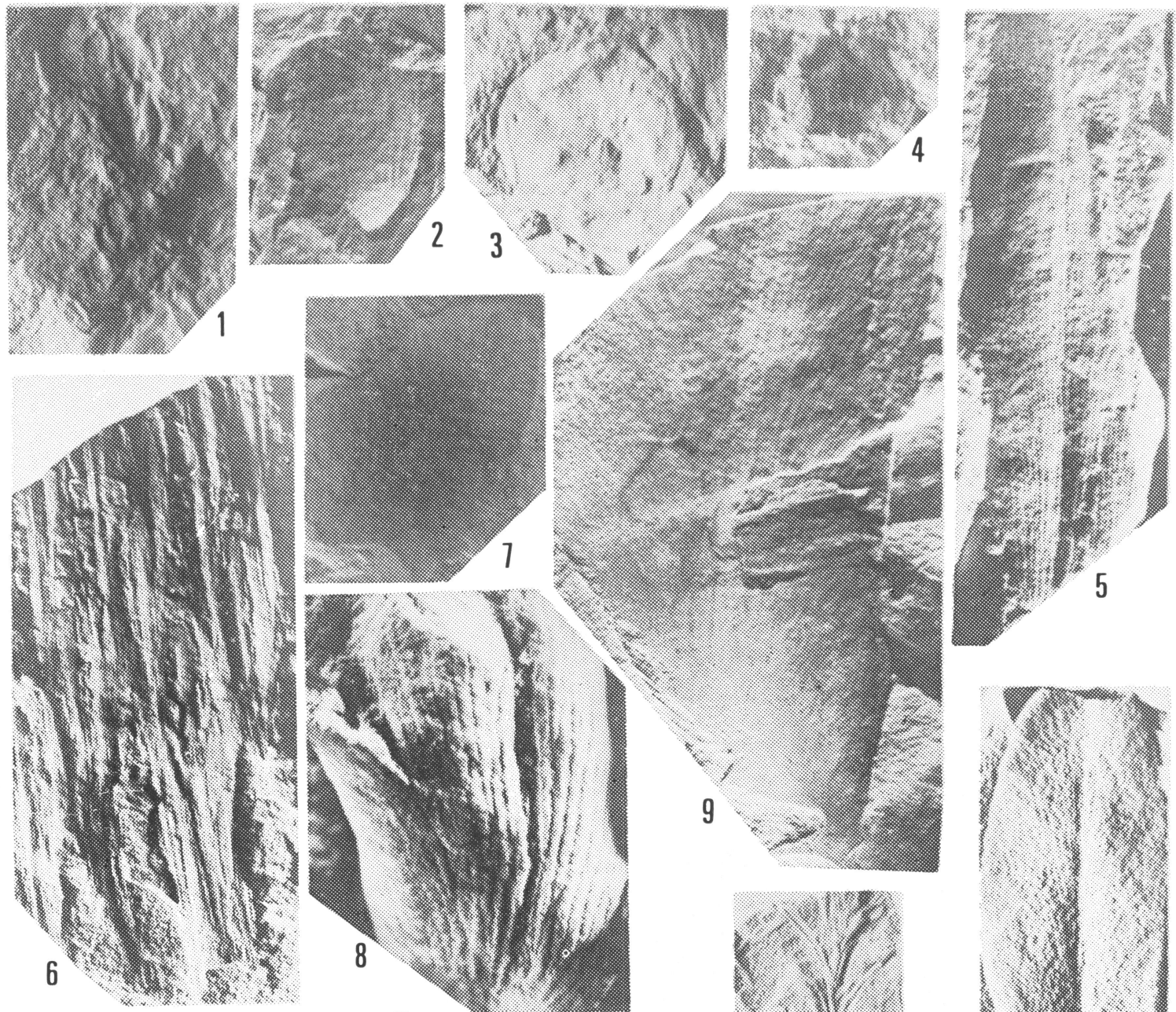

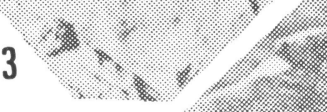
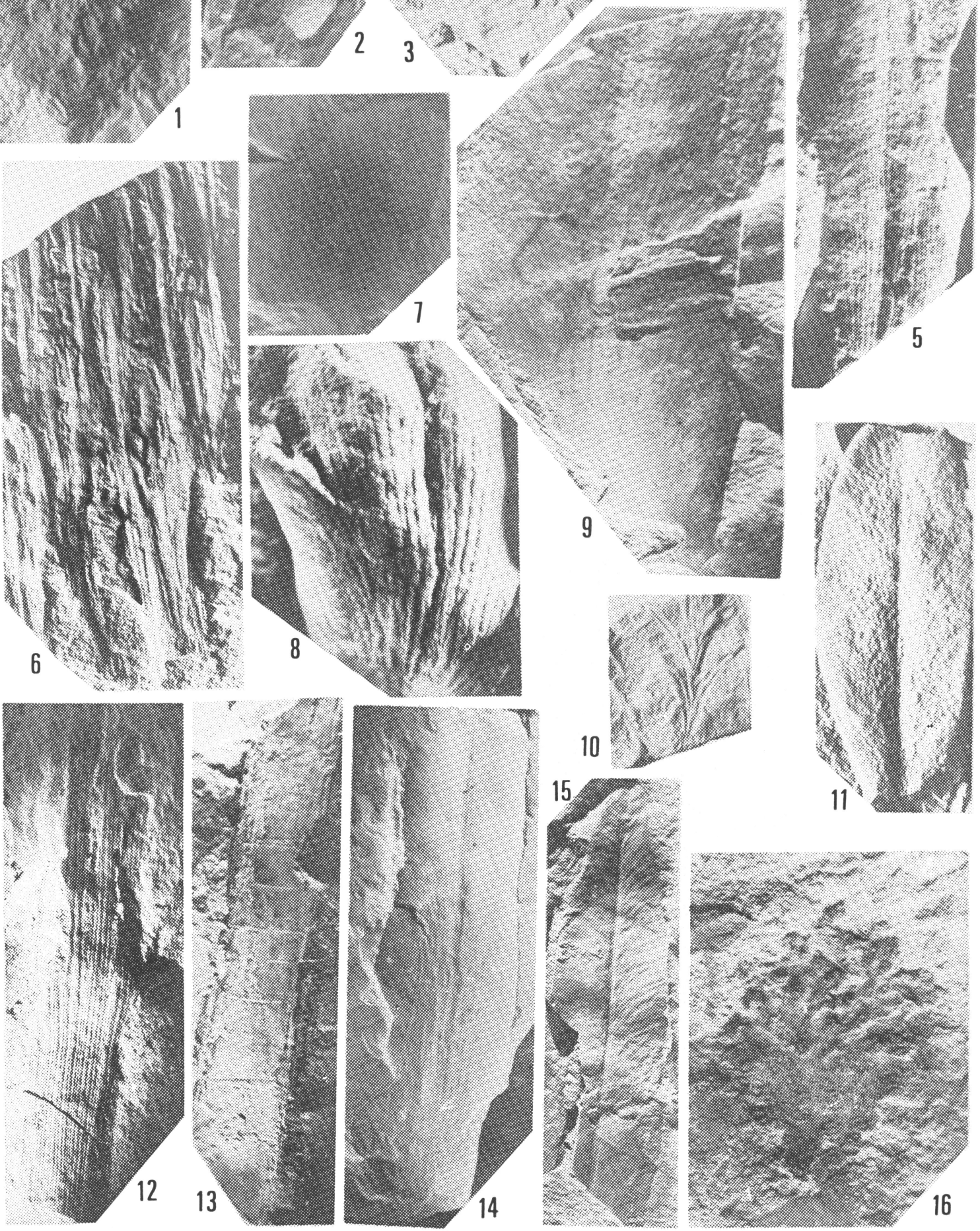


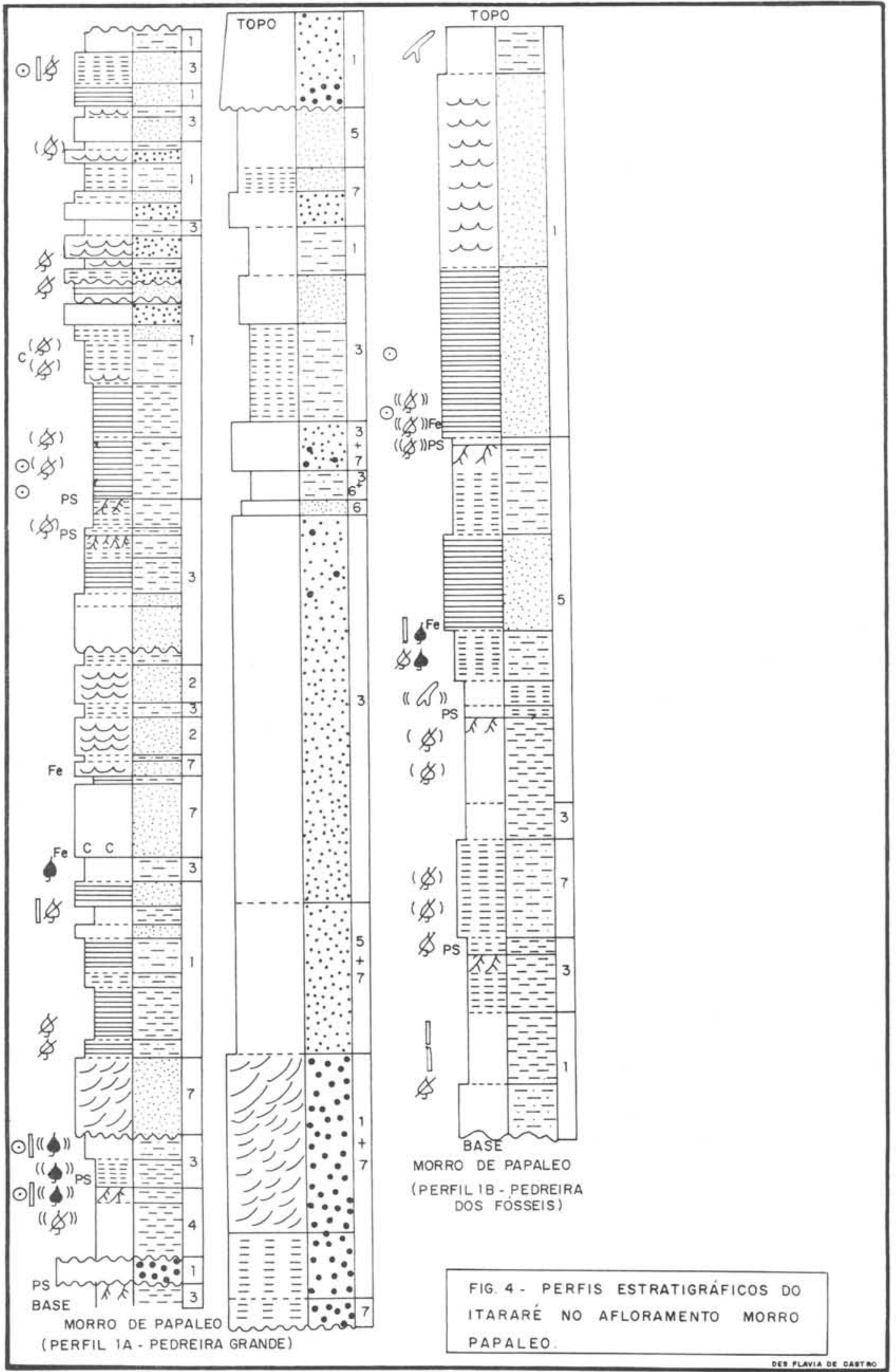


Paleobotânica e Areas Afins na América do Sul _ Bol. IG. Instituto de Geociências, USP, V. 11:31-189, 1980
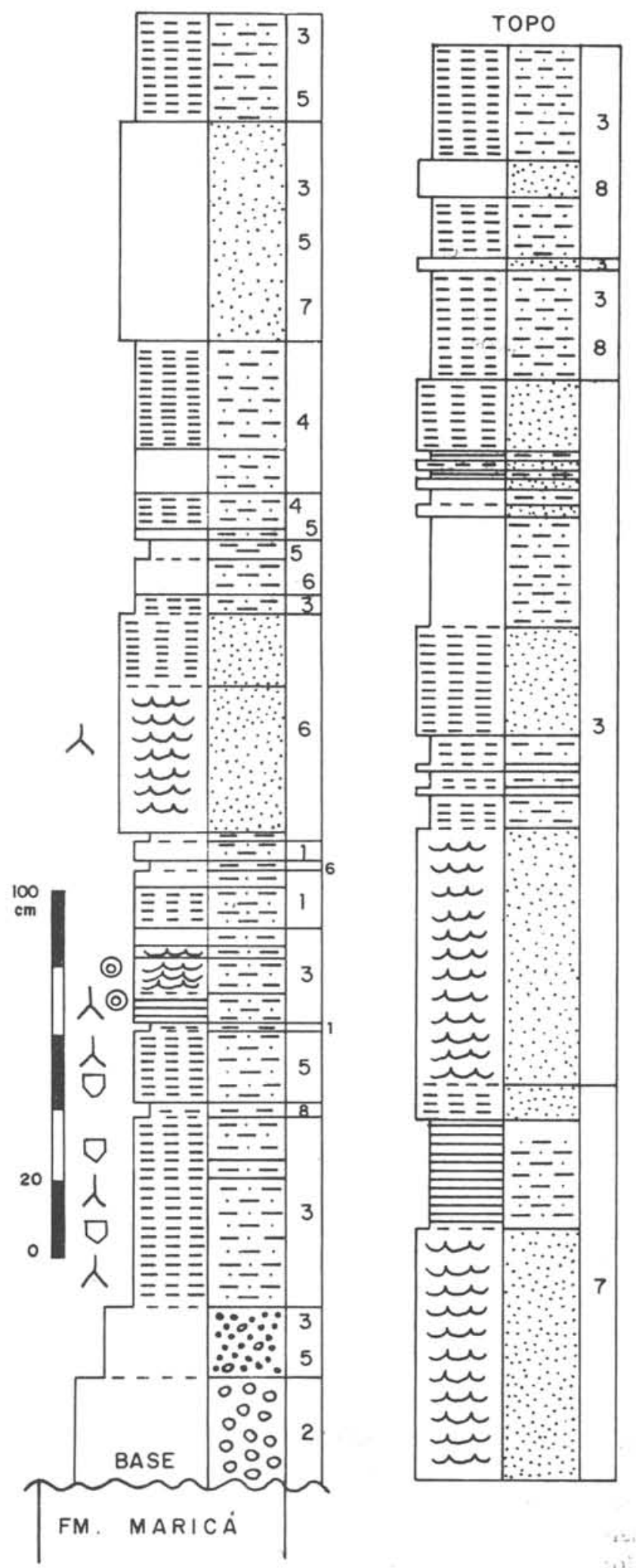

LITOLOGIA

OOO CONGLOMERADO

$\because 0 \%$ ARENITO MÉdIO C/ SEIXOS
DISPERSOS

$\because \because \quad \because$ ARENITO FINO

$\underline{\div \div \div} \quad$ SILTITO

E-ZA ARGILITO

ESTRUTURAS SEDIMENTARES

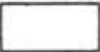

CAMADAS MACICAS

LAMINAÇÁO PLANo PARALELA

三 $\equiv$ LAMINAÇÃo POUCO DEFINIDA

U MARCAS DE ONDA

(?) NÓdULOS CHERT

כONTATOS ENTRE CAMADAS

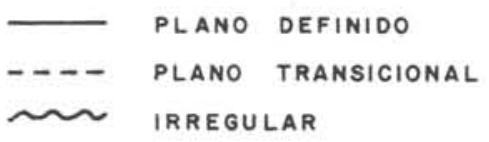

CONTEÚDO FOSSILÍFERO

人 espículas esponjas

$\square$ ESCAMAS DE PEIXE

CORES

$\begin{array}{lll}1 & - & \text { CASTANHAS } \\ 2 & - & \text { AMARELADAS } \\ 3 & - & \text { CINZENTAS } \\ 4 & - & \text { ROSADAS } \\ 5 & - & \text { PURPURAS } \\ 6 & - & \text { ALARANJADAS } \\ 7 & - & \text { AVERMELHADAS }\end{array}$

FIG. 5 - PERFIL ESTRATIGRÁFICO DO ITARARÉ NO AFLORAMENTO BUDO 
Escudo Sulriograndense, o qual representaria as áreas elevadas cobertas pela vegetação responsável pelos restos vegetais encontrados junto com os fósseis marinhos.

De acordo com essa interpretação, as plantas terrestres seriam alóctones, enquanto os pelecípodos, algas e demais fósseis poderiam ser considerados autóctones, não existindo niveis definidos, continentais ou marinhos que identifique um ciclo transgressivo.

$\mathrm{Na}$ área de Acampamento Velho se destaca uma diferença marcada de textura e espessura na seção inferior arenosa.

$\mathrm{O}$ perfil $\mathrm{B}$ apresenta $40 \mathrm{~m}$ de espessura de arenitos grossos a conglomeráticos, enquanto no perfil A chegam apenas a $6 \mathrm{~m}$, com arenitos médios.

A faixa de afloramentos é alongada no sentido NW-SE. Esta distribuição de espessuras no sentido transversal e a extensão relativa dos afloramentos pode representar, em parte, a disposição de um paleo-canal, encontrando-se o afloramento B numa parte central e o afloramento A numa área marginal.

\section{AFLORAMENTO MORRO PAPALÉO}

- Localização: De acordo com Dohms (1977) da rodovia BR-116 toma-se a estrada para a localidade de Mariana Pimentel, de onde segue-se pela estrada para Morro Papaléo até a mina de Rafael Papaléo e Cia. Ltda.

Em direção E-SE, pelo campo, chega-se à elevação mais próxima, na qual se encontra antiga escavação mineira que constitui o afloramento.

Folha Barão do Triunfo (SH22-0-1-2), município de Guaíba.

Obs.: Nesse trabalho são citados fósseis vegetais coletados nas localidades de Pedreira Grande e Pedreira dos Fósseis (fig. 4 - perfil 1A e 1B).

- Considerações Estratigráficas, Paleontológicas e Paleoambientais:

No afloramento Morro Papaléo as seqüências mais típicas são síltico-arenosas, esbranquiçadas e com estratificação tabular delgada. As camadas podem ser maciças ou apresentar estruturas internas (laminação plano-paralela ou marcas de ondas). Esse afloramento contém vários niveis de paleosolos, com boas paleosuperfícies e sistemas radiculares de poucos centímetros.
São freqüentes os níveis fossilíferos com impressões de restos vegetais (folhas, sementes, talos, frutificações) em regular estado de conservação.

Além destas seqüências, consideradas como depósitos de ambiente lacustre de águas rasas, nas seções superiores se intercalam depósitos arenosos mais grosseiros e sem restos fossilíferos, interpretados como fluviais.

Maiores considerações sobre aspectos litológicos e paleoambientais podem ser encontrados no trabalho de Andreis et alii (1979).

Correa da Silva $(1970,1972,1977$ e 1978) faz o estudo sistemático da associação paleoflorística encontrada neste afloramento citando:

\section{Paracalamites cf. australis Rigby 1969 \\ Glossopteris indica Schimper 1874 \\ Gangamopteris obovata (Carr.) White 1908 \\ Gangamopteris angustifolia McCoy 1875 \\ Gangamopteris buriadica Feistmantel 1879 \\ Noeggerathiopsis hislopi (Bunb.) Feist- mantel 1879 \\ Samaropsis seixasi (White) Seward 1917 Cornucarpus patagonicus (Ferra) Correa da Silva e Arrondo 1977 \\ Buriadia heterophylla (Feist.) Seward e Sahni \\ Ginkgophyllum criciumensis (Ribgy) Arch. e Arrondo cf. Nephropsis sp.}

Com base nos dados paleoflorísticos, a autora compara a tafoflora de Morro Papaléo com a registrada no Lubeckense A da Argentina (Sakmariano-Artinskiano).

As pesquisas agora realizadas acrescentam à associação o registro de Chiropteris sp. (est. III, fig. 3) e Rubidgea sp. (descrita por Andreis, R.R. Cazzulo-Klepzig, M; Guerra-Sommer, M, inédito) bem como uma frutificação provavelmente relacionada a Glossopteridophyta. E observada também a presença de estruturas vegetais enroladas, observadas por Correa da Silva (comunicação verbal).

Descrição da frutificação: O exemplar representa uma frutificação provavelmente feminina, formada por um pedúnculo de $3 \mathrm{~mm}$ de comprimento e $1,5 \mathrm{~mm}$ de largura e um corpo flabeliforme com $15 \mathrm{~mm}$ na sua parte mais larga. 
No corpo são encontrados, em distribuição irregular, pequenos corpúsculos arredondados, correspondentes aos óvulos, os quais não atingem $1 \mathrm{~mm}$ de diâmetro.

Essa frutificação pode ser comparada, estruturalmente, a formas de Ottokaria pela presença de um pedicelo longo e um corpo com óvulos, entretanto a ausência de brácteas marginais e a falta de limite nítido entre o corpo e o pedicelo dificultam a caracterização específica.
De acordo com Schopf (1976) as estruturas férteis de Glossopterídeas são caracterizadas, em conjunto, como Fertiliger.

Esse autor apresenta diferentes tipos morfológicos de capítulos entre os quais o tipo Ottokaria (Ottokaria bengalensis Zeiller 1902) é o que apresenta maior semelhança com o exemplar agora estudado; por esta razão esta frutificação fica aqui registrada apenas como Fertiliger.

\begin{tabular}{|c|c|c|c|c|c|c|c|}
\hline \multirow[t]{2}{*}{ QUADRO I } & \multicolumn{7}{|c|}{ REGISTROS PALEOBOTÃNICOS NO ITARARÉ NO R.G.S. } \\
\hline & Budó & $\begin{array}{l}\text { Acampamento } \\
\text { Velho }\end{array}$ & $\begin{array}{l}\text { Pinheiro } \\
\text { Machado }\end{array}$ & $\begin{array}{l}\text { Cambai } \\
\text { Grande }\end{array}$ & $\begin{array}{l}\text { Morro } \\
\text { Papaléo }\end{array}$ & $\begin{array}{l}\text { Fazenda } \\
\text { Goulart }\end{array}$ & Faxinal \\
\hline Algas indeterminadas & $x$ & $x$ & $x$ & $x$ & $\mathrm{x}$ & & \\
\hline Phyliotheca sp. & & $x$ & & & & & \\
\hline Paracalamites cf. australis Rigby & & $x$ & & & $\mathrm{x}$ & & $x$ \\
\hline Koretrophyllites sp. & & & & & & $\mathrm{x}$ & \\
\hline Glossopteris sp. & & $x$ & & & $\mathrm{x}$ & & $x$ \\
\hline Glossopteris indica Schimper & & $x$ & & & $x$ & & \\
\hline Gangamopteris sp. & & $x$ & & $x$ & $x$ & & $x$ \\
\hline Gangamopteris obovata (Carr.) & & & & & & & \\
\hline White & & $x$ & & $x$ & $\mathrm{x}$ & & \\
\hline Gangamopteris angustifolia McCoy & & $x$ & & $x$ & $x$ & & \\
\hline Gangamopteris buriadica & & & & & & & \\
\hline Feistmantel & & $x$ & & $x$ & $x$ & & \\
\hline Rubidgea sp. & & $x$ & & & $x$ & $x$ & $x$ \\
\hline $\begin{array}{l}\text { Noeggerathiopsis hislopi (Bunb) } \\
\text { Feist. }\end{array}$ & & & & & & & \\
\hline $\begin{array}{c}\text { Feist. } \\
\text { Cordaites sp. }\end{array}$ & & $x$ & & & $x$ & & \\
\hline $\begin{array}{l}\text { Cordaites sp. } \\
\text { Cordaites his/opi }\end{array}$ & & $X$ & & $x$ & & $X$ & $x$ \\
\hline $\begin{array}{l}\text { Cordaites hislopl } \\
\text { Buriadia heterophylla Seward e }\end{array}$ & & $x$ & & & & & \\
\hline Sahni & & & & & $x$ & & $x$ \\
\hline Ginkgophyllum criciumensis & & & & & & & \\
\hline Archangelsky e Arrondo & & & & & $x$ & $x$ & \\
\hline Chiropteris reniformis Kawasaki & $x$ & & & & $x$ & $x$ & \\
\hline Chiropteris sp. & & & & & $\mathrm{x}$ & $x$ & \\
\hline $\begin{array}{l}\text { Botrychiopsis plantianum } \\
\text { Carruthers }\end{array}$ & & $x$ & & & & $x$ & \\
\hline Botrychiopsis sp. & & $x$ & & & & $x$ & \\
\hline cf. Nephropsis & & & & & $x$ & & \\
\hline Cornucarpus patagonicus & & & & & & & \\
\hline e Arrondo & & & & & $x$ & & \\
\hline Samaropsis seixasi (White) Seward & & & & & $x$ & & $x$ \\
\hline Cordaicarpus sp. & & & & $x$ & & $x$ & $x$ \\
\hline Sementes gigantes não identificadas & & & & & & $\mathrm{x}$ & $x$ \\
\hline $\begin{array}{l}\text { Cone de gymnospermae não } \\
\text { identificado }\end{array}$ & & & & $x$ & & $x$ & \\
\hline
\end{tabular}


Tomando como referência o quadro 1 (modif. Correa da Silva 1978) nota-se a grande semelhança entre as tafoflórulas de Papaléo, Acampamento Velho e Faxinal.

Em relação às tafofloras estabelecidas por Rösler (1975 e 1978) para a Bacia do Paraná observa-se acentuada afinidade com a Tafoflora Transicional A - B. De acordo com Bernardes de Oliveira (1978) nos níveis estratigráficos do Grupo Itararé caracterizados por essa flora, o predomínio paleoflorístico cabe às Gangamopterídeas. Cabe salientar que no Morro Papaléo há uma mudança de proporção na ocorrência do complexo Gangamopteris Glossopteris, com maior representatividade de folhas do tipo Glossopteris.

\section{AFLORAMENTO BUDÓ}

- Localização: De acordo com Correa da Silva 1978, o afloramento Budó encontra-se situado nas proximidades da fazenda do mesmo nome, a $51,5 \mathrm{~km}$ da cidade de Bagé, na estrada Bagé-Lavras (RS 11). Este afloramento tem como coordenadas $50^{\circ} 6^{\prime} \mathrm{W}$ e $30^{\circ} 55^{\prime} \mathrm{S}$ e se localiza no Município de Lavras do Sul, numa faixa de afloramentos de direção SE-NW.

- Considerações estratigráficas: No afloramento Budó a seqüência do Grupo Itararé sobrepõe-se, em discordância angular, aos sedimentitos da Formação Maricá (Correa da Silva, 1978). A espessura máxima é de 7,90 metros, sem topo visivel.

A sequuência é constituída essencialmente por siltitos $(51 \%)$ e arenitos finos, às vezes sílti$\cos (43 \%)$, aos quais se associam escassos ruditos $(4 \%)$ e argilitos $(2 \%)$.

A porção basal está formada por ruditos e por arenitos médios, portadores de seixos subarredondados, dispersos, de até $7 \mathrm{~cm}$. O rudito, descrito como diamictito (Correa da Silva, op. cit.), exibe grande heterogeneidade textural e composicional; inclui seixos de natureza variada de até $20 \mathrm{~cm}$, distribuídos numa matriz siltico-arenosa. Os fragmentos de granito e migmatito predominam sobre os de riolitos, andesitos, xistos e sedimentitos, estes últimos pertencentes provavelmente à Formação Maricá (Correa da Silva op. cit.).

Em geral, as camadas podem ser maciças $(38 \%)$ ou apresentam laminação plano-paralela nítida $(9 \%)$ ou pouco definida $(48 \%)$; as escassas estruturas produzidas por marcas de ondas (5\%), parecem ser, algumas vezes, de tipo flaser. Normalmente, os arenitos exibem marcas de onda, enquanto que as laminações são bem mais freqüentes nos pelitos.

As cores mais comuns são cinzentas, de cinza claro a escuro, passando por variedades amareladas, esverdeadas ou rosadas $(60 \%)$. Além das pigmentações em laranja ( $24 \%$ e vermelho $(1 \%)$, ocorrem tons rosados $(7 \%)$, castanhos (3\%), amarelos (3\%) e púrpura (2\%).

A estratificação é tabular e a espessura das camadas oscila entre 5 e $40 \mathrm{~cm}$ nas porções basais, diminuindo para as porções médias e superiores, já que os arenitos apresentam variações entre 2 e $10 \mathrm{~cm}$ e os pelitos, entre 0,2 e $2 \mathrm{~cm}$.

Os contatos entre as camadas são planos, nítidos $(60 \%)$ ou transicionais $(40 \%)$. A ciclicidade é bem definida, sendo que a maior parte da seqüência exibe alternância de arenitos finos e siltitos e, em menor proporção, de siltitos com argilitos.

As rochas, muito litificadas, apresentam aspecto cerâmico e, às vezes, fratura conchoidal (Correa da Silva op. cit.).

- Conteúdo paleontológico: O conteúdo paleontológico do afloramento Budó é constituído por braquiópodos, escolecodontes, espiculas de esponjas, escamas e dentes de peixes, estruturas ainda não identificadas e restos vegetais.

Confirmando a idéia de Barcellos (1973) observa-se a ocorrência de um grande número de indivíduos mas pequeno número de espécies.

Uma observação importante é trazida pelos trabalhos de campo agora realizados: há grande abundância de impressões de pequenas estruturas de organismos marinhos, como espículas e ainda escamas e braquiópodos; entretanto restos vegetais não foram encontrados nem mesmo em forma fragmentária. O único registro de fóssil vegetal é feito por Dolianiti (1977) que o descreve como Chiropteris reniformis Kawasaki (est. II fig. 4 e 6).

Uma completa revisão dos registros fósseis para o afloramento Budó é apresentada no quadro de ocorrências da Formação Itararé por Correa da Silva (op. cit.), modificado agora neste trabalho (quadro I). 
- Interpretaçâo paleoambiental: A aparente falta de restos de organismos marinhos nas porções médias e superiores do perfil, e a maior freqüência de arenitos finos com marcas de onda (às vezes do tipo flaser), assim como a presença de alguns ciclos grano-decrescentes, sugerem algumas modificações paleoambientais. Deste modo, o mar aberto foi sendo substituído progressivamente por uma baía ou zona estuárica, indicando, em conseqüência, um lento processo regressivo. A ausência sistemática de restos vegetais indica que a região se manteve sempre afastada das áreas litorâneas.

Em geral, a pouca definição das estruturas laminares sugerem, além disso, a presença constante de águas salobras ou salgadas.

\section{CONCLUSÕES}

A revisão das tafoflórulas citadas para os afloramentos estudados indica a presença de associações de Flora Glossopteris na qual aparecem, ainda, formas "relictuais" do Carbonifero (Chiropteris, Koretrophyllites e Botrychiopsis) e elementos nórdicos (Cordaites).

As associações são similares, com nítido predomínio de Gymnospermae (com abundância de Glossopteridophyta) e menor ocorrência de Coniferophyta e Cordaitophyta. As Pteridophyta são escassamente representadas, ocorrendo apenas gêneros do Grupo das Sphenopsida.

A presença do gênero Rubidgea (Protoglossopterídea) nas tafoflórulas de Acampamento Velho e Morro Papaléo sugere que as associaçōes deveriam se situar na base da seqüência paleoflorística eogonduânica (intervalo Estefaniano-Sakmariano).

Nas tafoflórulas aparece um grande número de indivíduos e pequeno número de espécies, sugerindo um ambiente restrito (clima frio, periglacial, abundantes áreas baixas, vales de mangroves entre áreas elevadas).

A suposição da existência de mangroves é reforçada pelo tipo de estrutura radicular (pneumatóforos), característica das plantas tipo Glossopteris e Cordaites.
Representantes da fauna marinha ocorrem nos afloramentos Cambaí Grande, Acampamento Velho e Budó.

Considerando-se o conjunto dos afloramentos, podem se definir três biofacies características (quadro II).

Biofacies A - caracterizada por lagoas rasas com desenvolvimento de Glossopteridophyta e Cordaitophyta, preservadas in "situ" (mangrove, evoluindo para ambiente fluvial no topo). Esta biofacies corresponderia ao afloramento Morro Papaléo.

Biofacies B - caracterizada por ambiente de plataforma rasa, próximo à costa baixa, com fósseis marinhos, principalmente pelecípodos, e restos vegetais transportados e mal preservados. Representam esta biofacies os afloramentos Cambai Grande e Acampamento Velho.

Biofacies C - caracterizada por ambiente de plataforma de águas rasas (mais ou menos $50 \mathrm{~m}$ ) afastado da costa, com fósseis marinhos (escolecodontes, espinhas e escamas de peixes e branquiópodos). $\mathrm{O}$ afloramento Budó seria o exemplo para esse tipo de biofacies.

A passagem brusca de facies grosseira para siltitos marinhos nos afloramentos Cambaí Grande, Acampamento Velho e Budó indica uma rápida ingressão do mar que regride lentamente à medida em que é preenchida a faixa litorânea (afloramento Budó).

Com base nos dados obtidos, foi elaborado o quadro II, na tentativa de uma interpretação paleoambiental.

\section{AGRADECIMENTOS}

Os autores expressam seu agradecimento ao Prof. Renato Rodolfo Andreis, do Instituto de Geociências da UFRGS, pela valiosa colaboração deste trabalho e à Desenhista Flavia Castro, pela execução das ilustrações. 


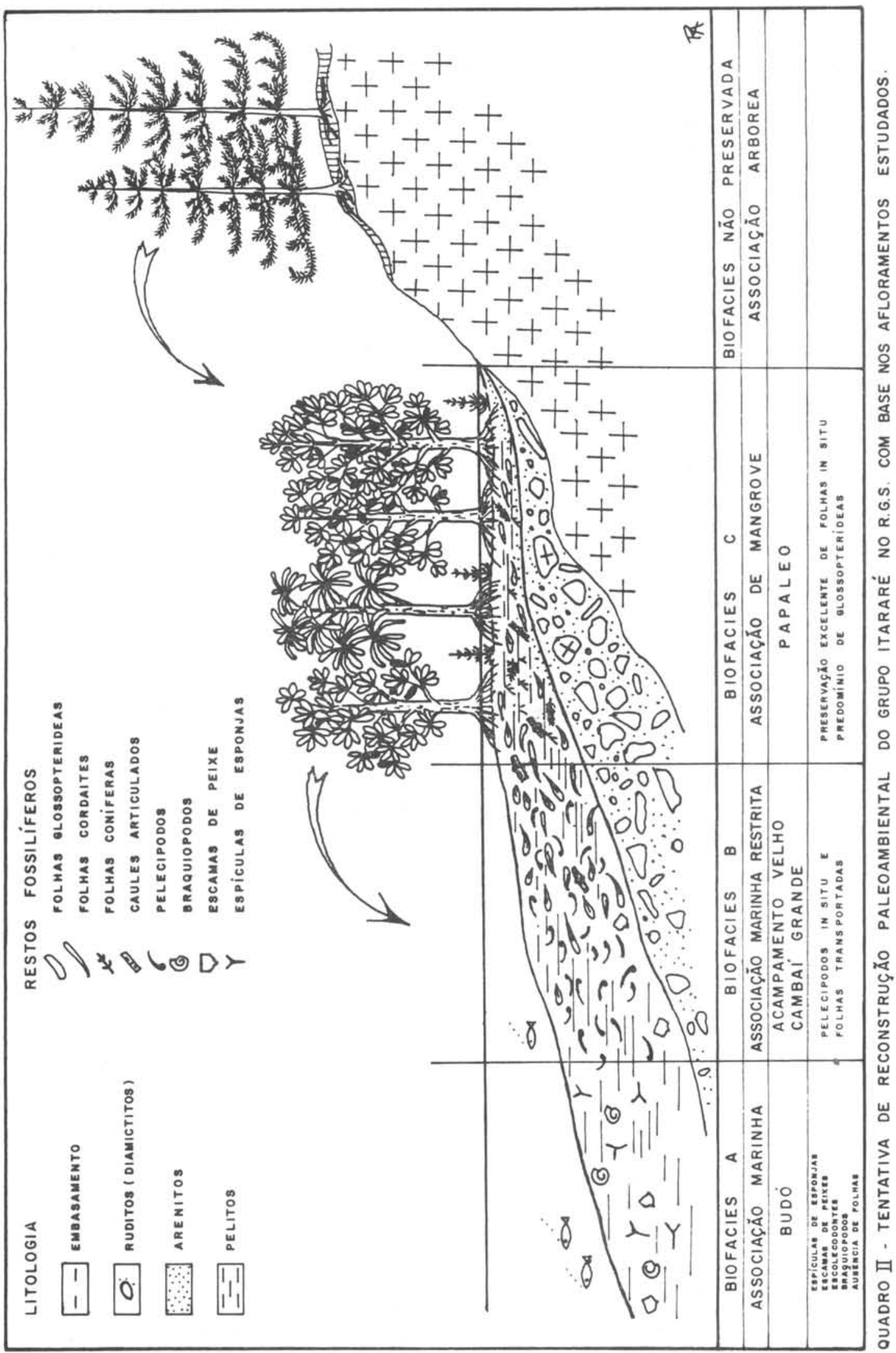




\section{BIBLIOGRAFIA}

ANDREIS, R.R.; CAZZULO-KLEPZIG, M. \& GUERRA-SOMMER, M. - 1979 - Interpretação paleoambiental e estudo paleobotânico e palinológico do Grupo Itararé, área de Faxinal, municipio de Guaiba, RS - IX Simpósio de Geologia do Nordeste, Natal - outubro de 1979 (no prelo).

ARCHANGELSKY, S. \& ARRONDO, O.G. - 1971 - Palaeophytologia Kurtziana III. 2. Estudio sobre el Genero Botrychiopsis Kurtz (Gondwanidium Gothan) del Carbonico-Permico Gondwanico. Ameghiniana B. A; 8 (3/4): 189-277.

ARCHANGELSKY, S. \& LEGUIZAMÓN, R.R. - 1978 - Elementos paleofloristicas en el Carbonico Superior de Malanzan. Sierra de los Llanos, La Rioja, Republica Argentina. I Congresso Latinoamericano de Paleontologia, B.A. (no prelo).

ARRONDO, O.G. - 1972 - Sintesis del conocimiento de las tafofloras del Paleozoico Superior de Argentina. An Ac. Bras. Cienc., R. Janeiro, 44: 37-50, Suplemento.

BARCELLOS, M.T. - 1973 - Estudo de escamas e dentes de peixes da facies Budó, Subgrupo Itararé, RGS. Tese (Mestrado) - Inst. Geoc, da UFRGS, 65 p., 7 fig. 32 fotos, 3 perfis.

BERNARDES DE OLIVEIRA, M.E. - 1978 - Ensaio sobre a utilização de caracteres biométricos das Glossopteridófitas em Estratigrafia - Advances in Palaeobotany and allied Sciences in Brazil - Boletim IG - Inst. Geoc. da USP, 9: 91-95.

BEURLEN, K.; MARTINS, E.A. \& SENA SOBọ, M. - 1955 - Formaçōes Gonduânicas do R.G. do Sul. Bol. do Museu Nac., N.S. Geol. R.J. 22:1-57, 33 fig.

CORREA DA SILVA, Z.C. - 1970 - Geologia e Estratigrafia do Grupo Tubarão na Folha Barão do Triunfo, mun. Guaíba, RS. Tese (Mestrado) - Curso de Pós-Graduação em Geociências, UFRGS. P.A., 152 p., inédito.

CORREA DA SILVA, Z.C. - 1978 - Observações sobre o Grupo Tubarão no RGS com especial destaque à estratigrafia da Form. Itararé, Pesquisas, Inst. Geoc. da UFRGS, 9: 9-62, 5 est., 3 fig.

CORREA DA SILVA, Z.C. \& ARRONDO, O.G. - 1977 - Tafoflora permiana de Mariana Pimentel, Munc. Guatba, $R S$ - Pesquisas, Inst. Geoc. UFRGS, 7:27-44, 1 fig., 2 pl.

DOHMS, M.H. - 1977 - Revisāo critica das citações da Flora Glossopteris para o R. G. do Sul - I. Folhas e Frutificaçōes - Pesquisas, Inst. Geociências, UFRGS, 7: 145-170, 7 figs., 2 quadros.

DOLIANITI, E. - 1954a - Gangamopteris angustifolia e Gangamopteris buriadica na Form. Maricá do RGS. Notas Prelim. e Estudos da Div. Geol. e Mineração, DNPM, RJ, 87: 16.

DOLIANITI, E. - 1954 b - A flora do Gondwana inferior em Sta. Catarina V-gênero Gangamopteris. Notas Prel. e Estudos, Divisão de Geol. e Mineração do DNPM, RJ. 89: 1-12.

FLORIN, R. - 1936 - Die fossilen Ginkgophyten von Franz-Joseph-Land nebst Erörterungen über vermeintliche Cordaitales mesozoischen Alters. 2. Allgemeiner Teil. Palaeontographica 82, abt. B (1-4): 1-72, pl. 1-6, text. fig. 1-8, Stuttgart.

MAITHY, P.K. - 1965 - Studies in the Glossopteris Flora of India. 18. Gymnospermic seeds and seed-bearing organs from the Karharbari Beds of the Giridish Coalfied. The Palaeobotanist 13 (1): 45-46, 2 fl. 20 fig., Lucknow.

MARTINS, E.A. \& SENA SOBọ, M. - 1950 - Novos fósseis e a idade da Formação Maricá, RGS. - Bol. do Mus. Nacional, N.S. Geol. do Rio de Janeiro, 8: 1-6, 4 figs., 1 mapa.

MEYEN, S.W. - 1963 - On the anatomy and nomenclature of leaves of the Angara cordaiteans. Paleontol. Zh., 3: 96-107, Moscou.

MEYEN, S.V. - 1967 - Phyllotheca - like plants from the Upper Palaeozoic Flora of Angaraland. Palaeontographica 133, abt. B: 1-33, fl. 1-12, Stuttgart. 
MEYEN, S.V. - 1971 - New data on relationship between Angara and Gondwana Late Palaeozoic Floras. In: IUGS Symp., Gondwana Stratigraphy, B. Aires 141-54, 11 text-fig., 1 est.

PANT, D.D. \& VERMA, B.K. - 1964 - The cuticular structure of Noeggerathiopsis Feist. and Cordaites Unger. Palaeontographica 115, abt. B; 21-44, Stuttgart.

RÖSLER, O. - 1973 - Tafofloras neopaleozóicas da Bacia do Paraná. II Congr. Latinoamericano de Geol. Resumos - p. 32, Caracas, 11-16, Nov. 73.

RÖSLER, O. - 1978 - The Brazilian Eogondwanic Floral Succesion - Advances in Palaeobotany and allied sciences - Bol. IG, Inst. Geociências USP, 9: 85-90, 3 fig.

SCHOPF, J.M. - 1976 - Morphologic interpretation of fertile structures in Glossopterid Gymnosperms. Review of Palaeobotany and Palynology, 21:25-64.

SEWARD, A.C. \& SAHNI, B. - 1920 - Indian Gondwana Plants: a revision. Mem. Geol. Surv. India, Palaeont. Indica, n.s., 7 (1): $1-54,7$ est., Calcutta,

SZUBERT, E.C. \& VERGARA, W. - 1967 - Mapeamento geologico da área VII da Quadrícula Coxilha do Tabuleiro, Porto Alegre. Trabalho de Graduação. Escola de Geologia. UFRGS. Inédito.

TEIXEIRA, J.T. \& RADAELLI, V.A. - 1967 - Mapeamento geologico da área III da Quadrícula Coxilha do Tabuleiro, Porto Alegre. Trabalho de Graduação, Escola de Geologia, UFRGS. Inédito.

\title{
REVISĀO FITOESTRATIGRĀFICA DO GRUPO ITARARÉ NO RIO GRANDE DO SUL. III - ÁREA DE FAXINAL, MUNICIIPIO DE GUAİBA, RIO GRANDE DO SUL.
}

\author{
MARGOT GUERRA-SOMMER \\ MIRIAM CAZZULO-KLEPZIG \\ MARLENI MARQUES-TOIGO
}

Curso de Pós-graduação em Geociências, UFRGS

\section{RESUMO}

A sequência estudada corresponde a facies areno-pelíticas do topo do Grupo Itararé na localidade de Faxinal, Folha Barão do Triunfo, RS e in dica ambiente lacustre com periódicas expansões e recuos das bordas do lago.

A tafoflórula é representada pelos gêneros Rubidgea, Paracalamites, Cordaites, Buriadia, Glossopteris, Gangamopteris, Cordaicarpus e Samaropsis. A associação palinológica é constituída principalmente por Puntatisporites, Granulatisporites, Calamospora, Leiotriletes, Cristatisporites (Pteridophyta), Potoniesporites e Plicatipollenites (Gymnospermae), estando as Glossopteridophyta escassamente representadas. 